\title{
THE MODERN GEOLOGICAL SURVEY
}

Sarah Day talks to British Geological Survey Director Karen Hanghøj about geoscience, outreach and why we need experts more than ever

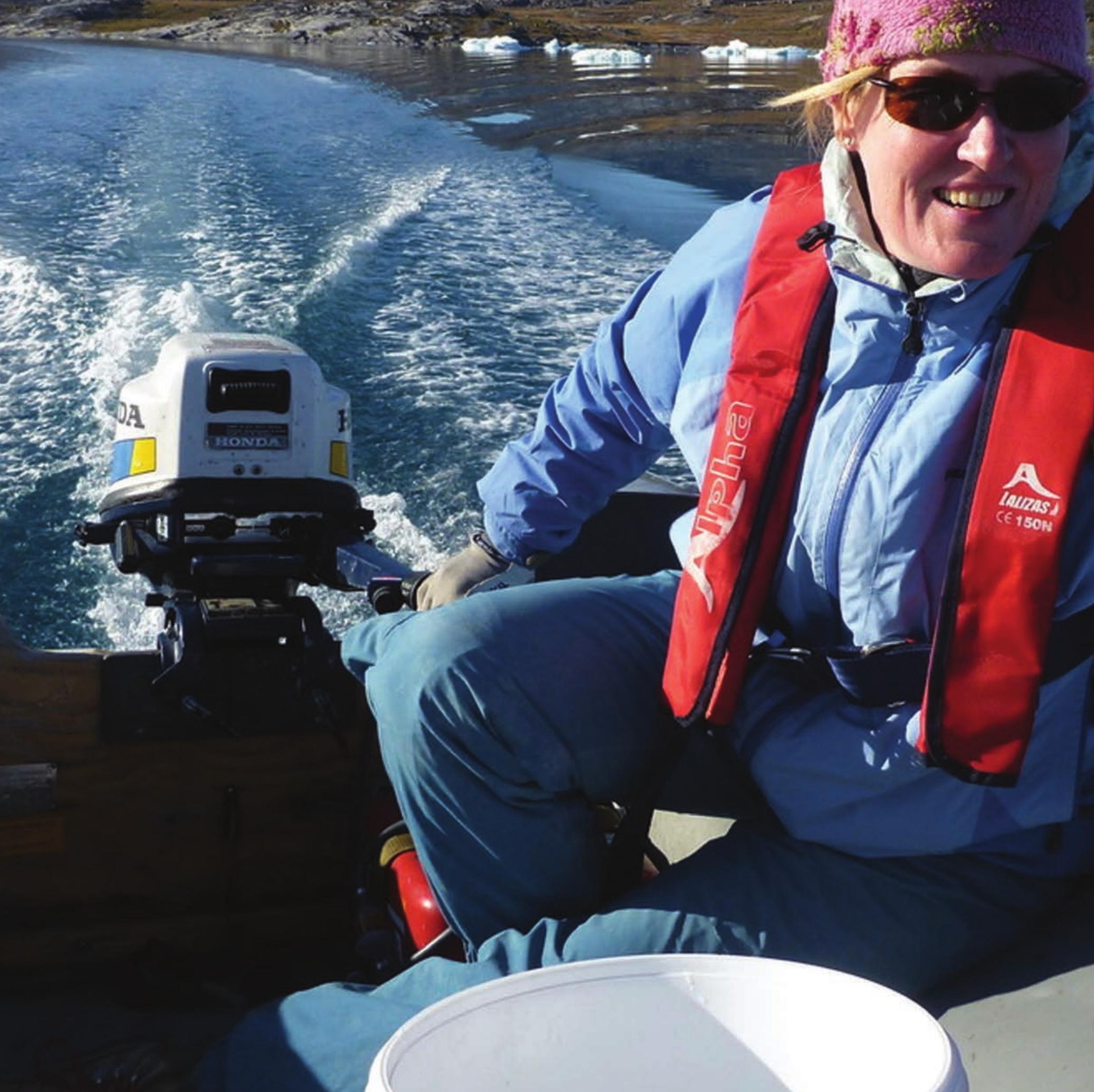




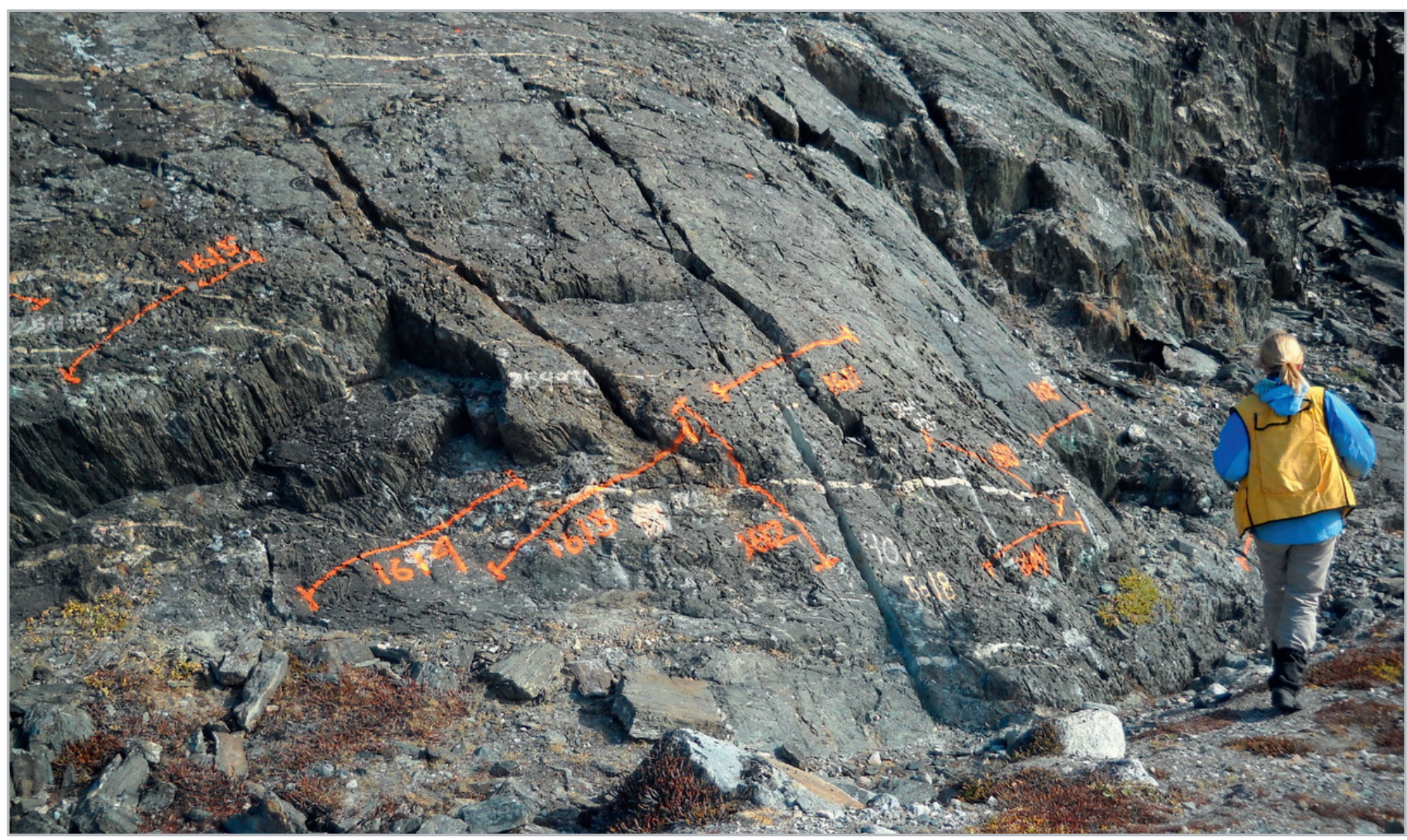

ground water, seismicity etc., but they're the right ten people, then we've done our job well.

'Some communication requires asking 'if we don't do this, is anyone else going to do it? And if not, and it's critically important to society, then it's important for us to do.'

Despite the work being done by the British Geological Survey and other organisations to promote the study of geoscience, student numbers are currently in decline. Hanghøj believes this is only partly down to a reputation as being linked with fossil fuel industries.

'Yes, it's partly that the subject's reputation has suffered from links to mining and especially oil in recent years, but I don't think that's the entire story. I think young people today think about things in a different way. They're attracted to new subjects like $\mathrm{AI}$ - and perhaps we haven't done enough to show students that the geosciences are part of topics like that too. Young people have to navigate such a huge variety of options now - we need to get better at selling ourselves. I think the BGS definitely has a role to play here.'

\section{Signal value}

Hanghøj is the first female Director of the Survey, which was founded in 1835. Unsurprisingly, it's a subject she's asked about often.

'It means a lot to me to be the director of an incredible geological research organization that's been around for a long time, but it doesn't mean a lot to me personally to be the first woman. I think what's important is what it means to other people and the signal it sends - it's about time!

'I can tell from the reaction to the announcement that my appointment had a tremendous signal value for female geoscientists, and that's incredibly important. I do sometimes wish we could focus on other things though. There's always going to be an element of that - we want women to be visible at the top, but we also don't want the most interesting thing about female directors to be that they're female.

'In the profession as a whole, we're moving very slowly in the right direction but it is too slow. When I was a Masters student, we were probably around $30 \%$ women, and when I became a PhD student that cohort was also at least $30 \%$. I'm not part of a $30 \%$ cohort any more.

There is something systemic that makes women leave the career path in geology, and we need to think really hard about it.
'We have to start thinking differently, about the environment scientists work in as a whole. With diversity more widely, particularly ethnic diversity, we're doing very badly. I think we're still only beginning to understand why, and how we can change.'

\section{A unique organisation}

Despite the challenges, Hanghøj is happy to be back working at a Geological Survey, combining interests in academic research, societal applications and industry which have been a feature of her career so far.

'It's been a steep learning curve in many ways, but in others, not at all, because I feel so at home. I'm interested in the core research, but also in what society needs from us, and that's what the modern Geological Survey is all about.

'To be able to provide credible advice, we need to be experts. The great advantage of a Survey is you have a lot of different people who have similar experience and overlapping expertise. So if a new problem shows up in society, industry or government, we have the critical mass to respond and contribute to finding new solutions. That's something pretty unique to an organisation like ours.' 

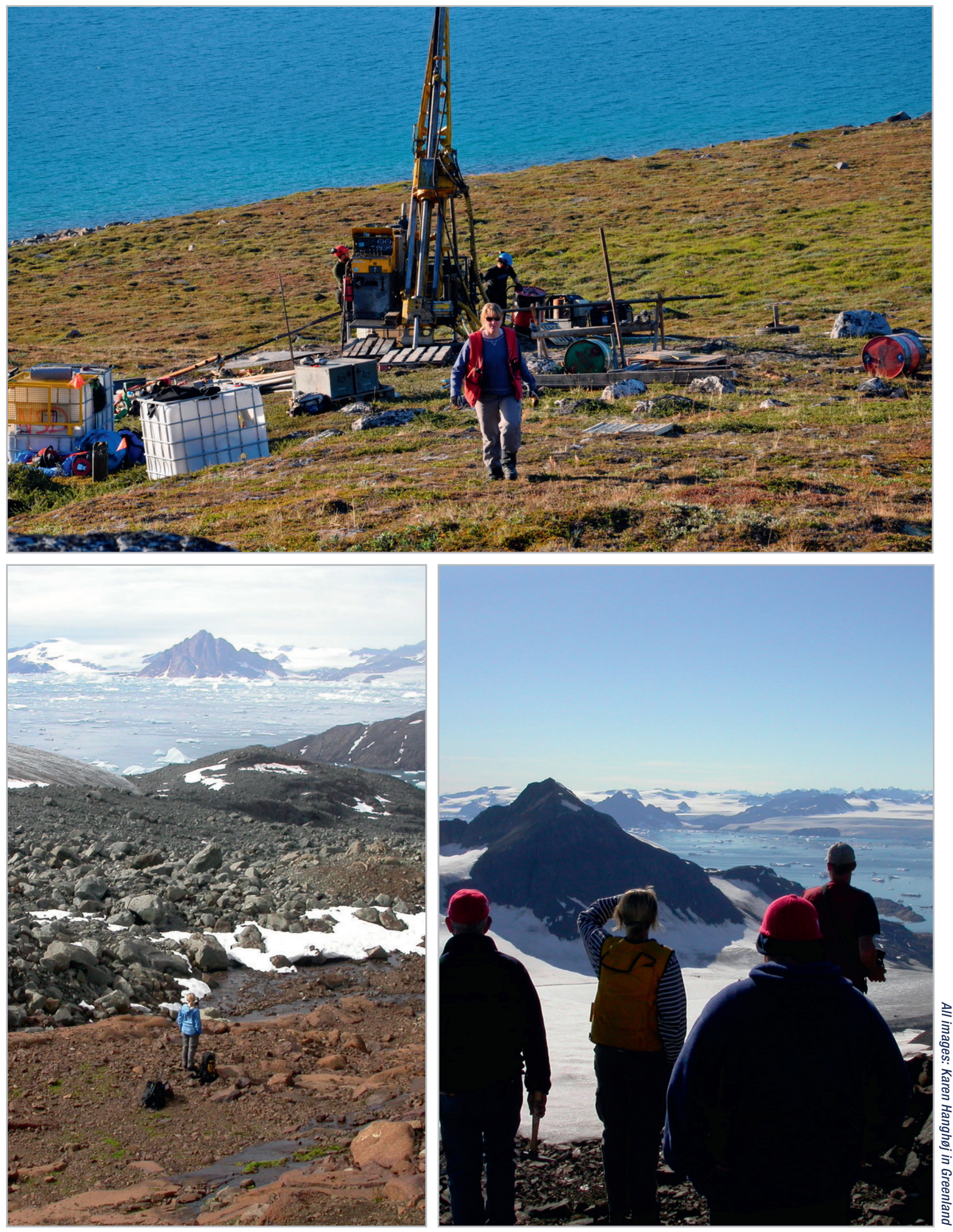